$7-29-2019$

\title{
House Calls Are Reaching the Tipping Point - Now We Need the Workforce
}

Thomas Cornwell

Follow this and additional works at: https://aah.org/jpcrr

Part of the Clinical and Medical Social Work Commons, Family Practice Nursing Commons, Geriatrics Commons, Health and Medical Administration Commons, Health Services Research Commons, Medical Education Commons, Medical Humanities Commons, and the Primary Care Commons

\section{Recommended Citation}

Cornwell T. House calls are reaching the tipping point - now we need the workforce. J Patient Cent Res Rev. 2019;6:188-91. doi: 10.17294/2330-0698.1719

Published quarterly by Midwest-based health system Advocate Aurora Health and indexed in PubMed Central, the Journal of Patient-Centered Research and Reviews (JPCRR) is an open access, peer-reviewed medical journal focused on disseminating scholarly works devoted to improving patient-centered care practices, health outcomes, and the patient experience. 


\title{
House Calls Are Reaching the Tipping Point - Now We Need the Workforce
}

\author{
Thomas Cornwell, MD \\ Home Centered Care Institute, Schaumburg, IL; Northwestern Medicine Regional Medical Group, Winfield, IL
}

\begin{abstract}
Home-based primary care (HBPC) improves the lives of high-cost, frail, homebound patients and their caregivers while reducing costs by keeping patients at home and reducing the use of hospitals and nursing homes. Several forces are behind the resurgence of HBPC, including the rapidly aging population, advancements in portable medical technology, evidence showing the value of HBPC, and improved payments for HBPC. There are 2 million to 4 million patients who could benefit from HBPC, but only $12 \%$ are receiving it. The number of these patients is expected to double over the next two decades. This requires a larger and better prepared HBPC workforce, making St. Clair and colleagues' article published within this same issue very timely. They showed residents exposed to HBPC had increased interests in providing HBPC in the future. They also found HBPC training fulfilled all 6 Accreditation Council of Graduate Medical Education core competencies and at least 16 of the 22 Family Medicine Milestone Project subcompetencies. Such medical education curricula are necessary to sufficiently develop a future workforce capable of appropriately providing HBPC to an increasing number of patients. (J Patient Cent Res Rev. 2019;6:188-191.)
\end{abstract}

Keywords $\quad$ home care; house calls; residency; frailty; health care costs; workforce; primary care

\section{The Modern-Day House Call Has Returned}

Home-based primary care (HBPC) improves the quality of life of caregivers and the lives of high-cost, medically complex, and functionally impaired patients while reducing costs by enabling patients to remain at home and avoid hospitals and nursing homes. Over the last century, there was a precipitous drop in medical house calls from $40 \%$ of all physician encounters in 1930 to less than $0.5 \%$ in 1996 as documented by the New England Journal of Medicine in "House Calls to the Elderly - A Vanishing Practice Among Physicians." However, shortly after this article was published, a resurgence in house calls began.

This editorial describes the forces behind this resurgence of house calls, including the aging of

Correspondence: Thomas Cornwell, MD,

Home Centered Care Institute, 1900 E. Golf Road, Suite 480, Schaumburg, IL 60173 (tcornwell@hccinstitute.org) society, advancements in portable technology, improved Medicare payments, and data showing the value of house calls. Additionally, improved payments incentivize the development of house call programs. With these improved payments, the rate-limiting factor is now going to be HBPC workforce development, which makes St. Clair and colleagues' article in this issue of Journal of Patient-Centered Research and Reviews, "Incorporating Home Visits in a Primary Care Residency Clinic: The Patient and Physician Experience (p. 203), ${ }^{, 2}$ so timely.

\section{Forces Behind the Return of House Calls}

The Aging of Society: The first baby boomers turned 65 in January 2011, and 10,000 boomers will join Medicare every day until 2029. The most rapidly growing age group in the United States is those 85 years and older, which is projected to quadruple between 2000 and 2050. ${ }^{3}$ Approximately half of this population needs assistance with at least 1 activity of daily living; one-quarter needs help with 2 , and 1 in 6 need help with 3 or more. ${ }^{4}$ This is an exploding 
homebound population. In 2011, 2 million individuals were homebound, and only $12 \%$ reported receiving HBPC. ${ }^{5}$ The number of homebound is expected to double over the next 20 years, which calls for adding $\mathrm{HBPC}$ experience to residency training.

Technology: Traditional diagnostic technology such as blood tests, electrocardiograms, X-rays, and ultrasounds are office- or hospital-centered, so patients must go to the doctor's office or hospital to have them done. Modern technology enables these diagnostic tests to be done in the patient's home. Labs can be done via point-of-care testing or drawn in the home and spun down using a portable centrifuge that plugs into a car's lighter. ${ }^{6-8}$ Many areas now have services that offer portable X-ray and ultrasound in the home, and some large house call programs provide these ancillary services, which also create added revenue. ${ }^{9}$

Smartphone apps can assist care in the home by providing rhythm strips, vision testing, drug databases, decision support, and much more. ${ }^{10,11}$ Finally, cloud-based electronic medical records allow access to patients' medical records virtually anywhere. All this enables the highest quality of medical care in the patient's home.

\section{Higher Medicare Fee-For-Service Payments:} In 1998, Medicare created higher-level Current Procedural Terminology (CPT) codes for house calls and started the process of doubling payments. This resulted in a $43 \%$ increase in annual house calls from 1.4 million in 1998 to 2.1 million in $2004,{ }^{12}$ the first increase in a century. In 2006, Medicare added higherlevel CPT codes for domiciliary visits (assisted living facilities and group homes) and more than doubled payments. This resulted in a marked increase in annual domiciliary visits from less than 1.3 million in 2006 to more than 3 million in $2016 .{ }^{13}$ Medicare also has added other CPT codes that support the work of HBPC providers. Examples include care plan oversight for overseeing home health and hospice; certifications and recertifications for home health; chronic care management; advance care planning; and prolonged non-face-to-face service before or after direct patient care. ${ }^{14,15}$ Despite these increased payments, fee-for-service will generally not sustain a house call practice financially because of the low volume of patients seen.

\section{Value of House Calls and New Value-Based Payments}

Health care spending is highly concentrated. The costliest $5 \%$ consume $50 \%$ of health care spending, and the top $1 \%$ consume $23 \%$ at an average cost of $\$ 107,130$ per patient. ${ }^{16}$ House calls provide care for these sickest patients in society and have been shown to reduce costs and improve patient and caregiver satisfaction significantly. Examples include:

- Analysis of the Veteran Administration's 2007 HBPC program (the largest in the country) found a nearly $60 \%$ reduction in hospital days, a $21 \%$ reduction in 30 -day readmissions, and an $89 \%$ reduction in VA nursing home days. The program also had the highest patient and caregiver satisfaction of any VA program. ${ }^{17}$

- Comparing $700 \mathrm{HBPC}$ to more than 2000 controls over 2 years at MedStar Washington Hospital Center in Washington, DC, found HBPC decreased hospitalizations by $9 \%$ and emergency room visits by $10 \%$. This resulted in $\$ 8400$ savings per patient and a total savings of $\$ 6.1$ million over the 2-year time frame. ${ }^{18}$

- U.S. Medical Management (USMM, Troy, MI) operates the only HBPC accountable care organization (ACO) in the country. In 2016, its second year, USMM generated over $\$ 44.5$ million in shared savings on approximately 18,000 patients in 14 states, making it the fourth most financially successful ACO out of 472. USMM generated an average savings of $\$ 2450$ per patient while achieving an overall quality score of $97 \%$. In year 3, USMM saved $\$ 45$ million on 20,750 patients. $^{19}$

- Independence at Home is a Centers for Medicare \& Medicaid Services demonstration involving 15 house call practices and 10,000 Medicare beneficiaries annually. In its first 4 years, the program saved $\$ 82$ million, making it the most successful Medicare demo. This program also showed improved quality metrics, including hospital follow-up within 48 hours, medication reconciliation, and discussion of advance directives. $^{20}$

HBPC's tremendous value creates significant opportunities with both existing and newly announced value-based payments and in working with financially at-risk entities like Medicare Advantage. HBPC 
can provide savings for Medicare Shared Savings Programs (eg, ACOs), as shown by USMM. Centers for Medicare \& Medicaid Services recently announced 2 new value-based payments, which could benefit HBPC. One is Primary Care First, which would provide a per-member-per-month (PMPM) payment for caring for patients with high-cost, complex chronic needs in addition to a flat visit fee and shared savings. ${ }^{21}$ The second program is Direct Contracting, which requires covering 5000 beneficiaries. ${ }^{22}$ Programs would receive risk-adjusted capitation and shared savings or could take on full risk. House call programs could join together to achieve the required 5000 patients.

House call programs also have successfully contracted with Medicare Advantage programs for a PMPM payment to care for high-cost patients. House call programs not only reduce costs on these patients, but they capture important diagnoses used in risk adjustment that determines payments for Medicare Advantage patients and predicted costs for ACOs and other shared savings programs. About $80 \%$ of ACOs reported using house calls for some of their patients. ${ }^{23}$ Capturing appropriate diagnoses shows the true disease burden of these homebound patients and can impact overall revenue more than the cost savings achieved by HBPC. Finally, by reducing gaps of care and achieving high patient satisfaction, HBPC helps improve quality scores for all programs and star ratings for Medicare Advantage.

\section{The Needed Workforce}

Now that an economic engine is developing to support HBPC, the rate-limiting factor is workforce development. This makes St. Clair and colleagues' article on incorporating home visits into residency training ${ }^{2}$ an important addition to the HBPC literature. The United States has a shortage of primary care providers, and a minority of medical schools and residencies teach HBPC. A full-time physician can care for 200-250 homebound patients and make 1600-2000 house calls per year. Yet, only 1000 HBPC providers make over 500 house calls annually in the United States. ${ }^{24}$ This small number performs half the nation's house calls. These high-volume providers are mainly in urban and suburban areas, and 12 rural states do not have even one high-volume provider. To fully care for the up to 4 million patients in need would require more than 7000 providers, though telemedicine has the potential to significantly reduce the required number.
The study by St. Clair et al reports small numbers but shows the potential value of exposing residents to HBPC as well as the teaching value of house calls. A full 100\% of patients valued the program, which is consistent with the high patient satisfaction scores HBPC programs receive. It is encouraging that $80 \%$ of residents stated they were likely to incorporate home visits in their future practices from just this brief exposure. ${ }^{2}$

As the authors noted, house call education is of great benefit even if physicians do not subsequently make house calls. House call patients are complex and provide opportunities to teach geriatric principles, multiple chronic condition care, team-based care (including working with home health and hospice), transitions of care, palliative and end-of-life care, community resources, and the impact of social determinants of health. It is a testimony to the teaching value of house calls that they have been shown to fulfill all 6 Accreditation Council of Graduate Medical Education core competencies and at least 16 of the 22 Family Medicine Milestone Project subcompetencies. ${ }^{25,26}$

\section{Summary}

We need to push home-based primary care forward, without delay. In addition to developing medical school and residency curricula to expose learners to both the clinical and practice management aspects of HBPC, the formulation of medical educational guidelines on how to provide both HBPC shadowing and longitudinal HBPC experiences is warranted.

\section{Conflicts of Interest}

Dr Cornwell is chief executive officer of Home Centered Care Institute, a not-for-profit organization dedicated to expanding house call practices throughout the nation.

\section{References}

1. Meyer GS, Gibbons RV. House calls to the elderly - a vanishing practice among physicians. N Engl J Med. 1997;337:1815-20. $\underline{\text { CrossRef }}$

2. St. Clair MC, Kram JJ, Sundberg G. Incorporating home visits in a primary care residency clinic: the patient and physician experience. J Patient Cent Res Rev. 2019;6:203-9.

3. West LA, Cole S, Goodkind D, He W. 65+ in the United States: 2010. Issued 2014 Jun 30. https://www.census.gov/content/ dam/Census/library/publications/2014/demo/p23-212.pdf. Accessed June 1, 2019.

4. Hagen S; Congressional Budget Office (US). Rising demand for long-term services and supports for elderly people. Published 2013 Jun 26. https://www.cbo.gov/sites/default/ files/113th-congress-2013-2014/reports/44363-ltc.pdf. Accessed June 1, 2019. 
5. Ornstein KA, Leff B, Covinsky K, et al. Epidemiology of the homebound population in the United States. JAMA Intern Med. 2015;175:1180-6. CrossRef

6. Drucker Diagnostics. Mobile phlebotomy centrifuges. https:// druckerdiagnostics.com/mobile-phlebotomy/. Accessed June 1, 2019.

7. LW Scientific. Portafuge centrifuge. https://www.lwscientific. com/products/usa-portafuge-8-place?variant=16899378113. Accessed June 1, 2019.

8. Heathrow Scientific. Portable centrifuge kit. https://www. heathrowscientific.com/portable-centrifuge-kit-2. Accessed June 1, 2019.

9. Landers A, Ryan B. The use of bedside ultrasound and community-based paracentesis in a palliative care service. $J$ Prim Health Care. 2014;6(2):148-51.

10. Baquero GA, Banchs JE, Ahmed S, Naccarelli GV, Luck JC. Surface 12 lead electrocardiogram recordings using smart phone technology. J Electrocardiol. 2015;48(1):1-7. CrossRef

11. Pathipati AS, Wood EH, Lam CK, Sáles CS, Moshfeghi DM. Visual acuity measured with a smartphone app is more accurate than Snellen testing by emergency department providers. Graefes Arch Clin Exp Ophthalmol. 2016;254:1175-80. CrossRef

12. Landers SH, Gunn PW, Flocke SA, et al. Trends in house calls to Medicare beneficiaries. JAMA. 2005;294:2431-6. CrossRef

13. The Moran Company. Physician/supplier procedure summary (PSPS) master record file for Medicare Part B summary data, 2005-2016. Data accessed by the American Academy of Home Care Medicine. The Moran Company: Arlington, VA, 2017.

14. CGS Administrators, LLC. Care plan oversight services for patients receiving care through home health agencies or hospices. Posted 2014 May 23. https://www.cgsmedicare.com/partb/pubs/ news/2014/0514/cope25747.html. Accessed June 1, 2019.

15. Nicoletti B. How to document and bill care plan oversight. Fam Pract Manag. 2005;12(5):23-5.

16. National Institute for Health Care Management. The concentration of U.S. health care spending. Posted 2017 Jul. https://www.nihcm.org/categories/concentration-of-us-healthcare-spending. Accessed June 1, 2019.
17. Edes T, Kinosian B, Vuckovic NH, Nichols LO, Becker MM, Hossain M. Better access, quality, and cost for clinically complex veterans with home-based primary care. $\mathrm{J} \mathrm{Am} \mathrm{Geriatr}$ Soc. 2014;62:1954-61. CrossRef

18. De Jonge KE, Jamshed N, Gilden D, Kubisiak J, Bruce SR, Taler G. Effects of home-based primary care on Medicare costs in high-risk elders. J Am Geriatr Soc. 2014;62:1825-31. CrossRef

19. Saunders R, Bleser W, Japinga M. Serious illness approaches by ACOs: U.S. Medical Management. Published 2019 Apr 25. https://healthpolicy.duke.edu/sites/default/files/u31/case study_1_-_usmm.pdf. Accessed June 12, 2019.

20. Centers for Medicare \& Medicaid Services. Independence at Home Demonstration. Last updated 2019 May 23. https:// innovation.cms.gov/initiatives/independence-at-home/. Accessed June 12, 2019.

21. Centers for Medicare \& Medicaid Services. Last updated 2019 Jun 20. https://innovation.cms.gov/initiatives/primary-carefirst-model-options/. Accessed June 20, 2019.

22. Centers for Medicare \& Medicaid Services. Posted 2019 Apr 22. https://www.cms.gov/newsroom/fact-sheets/directcontracting. Accessed June 1, 2019.

23. Fraze TK, Beidler LB, Briggs ADM, Colla CH. 'Eyes in the home': ACOs use home visits to improve care management, identify needs, and reduce hospital use. Health Aff (Millwood). 2019;38:1021-7. CrossRef

24. Yao N, Ritchie C, Camacho F, Leff B. Geographic concentration of home-based medical care providers. Health Aff (Millwood). 2016;35:1404-9. CrossRef

25. Hayashi J, Christmas C. House calls and the ACGME competencies. Teach Learn Med. 2009;21:140-7. CrossRef

26. Sairenji T, Wilson SA, D'Amico F, Peterson LE. Training family medicine residents to perform home visits: a CERA survey. J Grad Med Educ. 2017;9:90-6. CrossRef

(C) 2019 Aurora Health Care, Inc. 